\title{
Effects of Flexibility, Security, and Information Features on Supplier Participation in the Sharing Economy: An Empirical Study
}

\author{
Soo Jeong (Chris) Hong \\ Pepperdine University \\ soojeong.hong@pepper \\ dine.edu
}

\author{
Johannes M. Bauer \\ Michigan State \\ University \\ $\underline{\text { bauerj@msu.edu }}$
}

\author{
Kwangjin Lee \\ Pepperdine University \\ kwangjin.lee@pepperdi \\ ne.edu
}

\author{
Nelson F. Granados \\ Pepperdine University \\ nelson.granados@pepp \\ erdine.edu
}

\begin{abstract}
Firms in the sharing economy typically offer higher flexibility but lower security of working conditions. In response to challenges from suppliers and policy makers, several platform companies are reconsidering their approach. This study examines the effects of offering sharing economy suppliers a menu of contract options, differentiated by varying levels of flexibility, security, and information transparency on their willingness to work for a platform. We focus on ridesharing, one of the largest sectors in the sharing economy, but the insights translate to other segments of this emerging sector. Using a discrete choice experiment, we find drivers' willingness to work for ridesharing generally increases when the platform offers diversified combinations of flexibility, security, and transparency. We also find evidence that suppliers' preferences to participate in the sharing economy are influenced by the working conditions in their alternative employment options.
\end{abstract}

\section{Introduction}

Innovative platform businesses are transforming the nature of employment relations and the working conditions of suppliers. Often referred to as the "sharing economy," this emerging class of activities comprises a broad range of services that are based on shared access to assets (e.g., apartments, cars), skills (e.g., consulting, crafts, driving), or both (e.g., ridesharing) [17]. These platforms serve as a digital intermediary between suppliers (e.g., Uber drivers, Airbnb hosts) and consumers (e.g., Uber passengers, Airbnb guests). To maintain a sustainable platform business, managers must design user-friendly ICT interfaces and develop a critical mass of supply and demand on the platform [43]. But with increasing competition and regulations in the space, building a sustainable, profitable platform business is a challenge.

The platform economy typically provides higher flexibility for suppliers, but it offers lower security than standard employment. Platform owners typically treat suppliers as independent contractors rather than as employees. Using court and legal challenges as well as strikes, Uber and Lyft drivers have protested to demand better job security. Legal measures to improve the standing of drivers have been adopted in several states and countries and more are pending. Given these and other challenges, platforms have yet to generate profits.

One of the challenges in the sharing economy is to secure the level and diversity of supply of services demanded by consumers. Understanding the motivations and deterrents of suppliers is essential to attract them and to scale the operation. There is evidence that the value placed on the flexibility of where and when to work [21], lower entry barriers for suppliers than in traditional labor markets, and the improved ability to monetize skills and resources are the main reasons for the fast influx of participants into the sharing economy. However, irregular work, fast changing business structures, and incomplete legislation may create uncertainty as to the sustainability of income and the longevity of jobs. These factors may reduce the willingness of suppliers to offer their service in a platform.

To secure participation by the required number of suppliers, firms must develop governance models that balance these competing factors. This requires a good understanding of suppliers' heterogeneous preferences for flexibility and security to efficiently minimize conflicts, reduce negotiation costs, and eventually grow and sustain service supply. While there has been substantial attention on adoption of sharing economy services by consumers, the role of flexibility and security for suppliers of services in the platform economy has received only limited attention in prior research.

In addition to flexibility and security, we investigate unique information features that are exclusively available in digital platforms. Since a platform is a marketplace where suppliers make work decisions, design of transparency strategies may influence the willingness of suppliers to work with the 
platform. While prior studies on transparency in IS have primarily focused on $\mathrm{B} 2 \mathrm{~B}[49]$ or $\mathrm{B} 2 \mathrm{C}[19,20]$ relationships, the effect of participants' information transparency in P2P markets has not been fully examined. To reduce these gaps, our study aims to answer the following research questions:

1) How do flexibility and security of working conditions affect the willingness of suppliers to work with a sharing economy platform?

2) How do information features that are available only on a digital platform affect the willingness of suppliers to work with the platform?

This study focuses on ridesharing services, one of the largest segments of the sharing economy. Using discrete choice experiments, we examine factors related to the information features of the platform and the design of the work conditions, particularly the balance of flexibility and security on the decision to work. Moreover, we explore the relationship between the decision to offer services in a platform and the flexibility and security of alternate job options. This study expands extant research on the sharing economy and on platform governance. It also contributes to one perspective in labor economics that asserts a positive relationship between flexibility and security (referred to as "flexicurity"). To our best knowledge, this is a first study investigating the effects of offering different levels of flexibility and security on the willingness to supply services in a platform. The findings shed light for platform businesses in general, including space rental, food delivery, and errand services platforms.

The remainder of this paper is organized as follows: The next section reviews relevant studies on platform governance, information transparency, and flexicurity to then develop key testable hypotheses. We then describe the data and research design, and report results. The concluding section discusses contributions and suggests future directions for research.

\section{Institutional and theoretical foundations}

\subsection{Platform governance in the sharing economy}

The IS field uses the term "platform" in multiple research contexts. Accordingly, several concepts of "platform governance" have been proposed (e.g., [11, 18]). Summarizing common traits of platform governance described in the prior literature [29], platform governance is "a multi-dimensional concept" controlling dynamically managed decision-making processes in a platform ecosystem [7, 38, 45], by using a structure, power, processes, and mechanisms [45].
Tiwana [44] implies that the purpose of platforms is to organize and coordinate wealth creation. Parker, Van Alstyne, and Choudary [35] clarify that the purpose of good platform governance is "to create wealth, fairly distributed among all those who add value." To achieve such fairness, platform owners must resolve conflicts among stakeholders of the platform community. As conflicts to distribute the newly created wealth may aggravate undesirable digital inequality $[13,22]$, the importance of good governance has become an important focus.

While there exists substantial research on governance of a platform's owner-developer relationship $[10,39,45]$ and owner-consumer relationship [24, 37], the owner-supplier relationship has not been investigated in comparable detail [29]. Prior studies of platform businesses have examined laws [31], norms [16], architecture [36], and pricing [4, $47,48]$ as means of platform governance [35]. Recently, contracts governing relations among participants in the platform ecosystem have received increasing (but still limited) attention $[10,30]$. Conceptually, this study analyzes contracts as a tool of platform governance that may be employed to manage conflicts and reconcile tensions between platform owners and suppliers, in line with ideas suggested by platform cooperativism [41].

In the case of ridesharing services, platform owners delegate to suppliers the decision on when and where to work. In turn, suppliers delegate to the platform owner the decision on whom they provide their service to or the access to a resource, as well as the payment amount. This attribution of decision making creates potentially difficult incentive problems. In the prevailing competitive work environment, sharing economy suppliers may need to accept lower compensation [32] and lower protection [15] than traditional jobs. As a result, suppliers may be relatively worse off, and in the long term, economic disparity may deepen [8, 42]. Thus, the role of working conditions as a key factor to influence suppliers' utility and to attract and retain them in a platform remains an important issue to be researched.

\subsection{Information transparency and platform design}

Managing information transparency has become easier as ICT advances. Firms may utilize transparency strategies when designing a digital platform to draw more suppliers and consumers. The transparency strategy includes not only revealing but also concealing information to participants.

Prior studies in IS have mainly investigated B2B or $\mathrm{B} 2 \mathrm{C}$ markets $[12,20,49]$. In $\mathrm{B} 2 \mathrm{~B}$ and $\mathrm{B} 2 \mathrm{C}$ markets, 
information of products, prices, inventory, cost, or process is typically disclosed by suppliers or firms to consumers or competitors [20]. In P2P sharing economy markets, suppliers also want to receive information about consumers because there is a risk involved in sharing access to their properties. Thus, platform owners disclose consumer information to reduce information asymmetry and establish trust of the digital marketplace [40].

In the sharing economy, platform owners have to handle participants' concerns about misuse of private information which can be exposed as they receive or provide services [2]. In particular, firms may conceal certain information to relieve suppliers' privacy concerns. The key is to provide an effective means of communication between suppliers and consumers that creates a trustworthy environment that suppliers and consumers perceive as efficient and safe to transact.

\subsection{Labor supply and flexicurity}

Many suppliers in the sharing economy hold other jobs. Thus, in addition to the role of flexibility and security in the sharing economy, a potential interaction exists with these other jobs. In traditional labor economics, individual labor supply is the outcome of two interrelated decisions: whether to work at all, and, if so, for how long. The opportunity cost of leisure, wealth, and preferences are usually regarded as the most important components in decisions to work [14]. The wage rate is considered the opportunity cost of one hour of leisure, and total income is often a proxy for total wealth [14]. Workers' preferences for other aspects like types of industry, flexibility of work hours, and benefit plans may vary depending on individual demographic factors such as age, educational attainment, and household income.

Job flexibility and security have long been studied as major institutional aspects influencing a decision to work. There are two different perspectives on the relationship between job flexibility and security: the trade-off theory and the flexicurity hypothesis, initially proposed in the context of labor reforms in the Netherlands and Denmark in the late 1990s [6, 32]. The first view posits that a negative relationship exists between the degree of flexibility and security. In other words, a higher level of flexibility can only be reached by reducing the degree of job security. The flexicurity hypothesis sees the relationship between flexibility and security as positive [28]. For example, a generous income security policy motivates risk averse workers to more proactively change jobs, contributing to flexibility in the labor market. ${ }^{1}$

Whereas much of the flexicurity discussion focuses on employment flexibility and income security at the labor market-level, this study utilizes the concept to investigate individual-level interactions. As many suppliers hold other jobs, we explore how the flexibility and security of an individual's job outside the sharing economy relates to activities in the sharing economy. For example, if a sharing economy platform structures contracts so a supplier can make choices to balance work flexibility and security, it may compensate for the lack of flexibility or security in the supplier's main alternative job. In this way, the sharing economy job may increase the overall perceived flexibility and security, so the supplier does not have to relinquish one of the two.

\section{Conceptual framework and hypotheses development}

Starting from gaps in research on the sharing economy, platform governance, and the flexicurity thesis, we examine ridesharing suppliers' preferences for different combinations of labor contract conditions using an online choice experiment. Figure 1 depicts the set of questions explored in this study.

The hypothetical contract conditions, which may influence perceived flexibility and security and eventually affect suppliers' willingness to work, were identified through a multi-pronged approach, including a review of the literature on job satisfaction (e.g., $[1,3$, 5]), recent public discussions regarding ridesharing (e.g., [9, 50]), six interviews, and 47 surveys of ridesharing suppliers and a ridesharing expert.

Considering that the capacity of the human brain to compare permutations of choice options with multiple attributes is limited, only the seven most salient attributes were included in the choice sets. A set of attributes is composed of both contractual and information transparency design dimensions of ridesharing services. Contractual conditions include options that are currently not offered by ridesharing services. To obtain an estimate of drivers' perceived value of information transparency, we also include important information features of ridesharing apps that would not be readily available if a supplier chose another platform.

\footnotetext{
1 Although there are a variety of opinions concerning the most effective components and formula of the flexicurity concept depending on countries and economic circumstances, the core notion is the complementarity of flexibility (e.g., employment flexibility) and security (e.g., income security).
} 


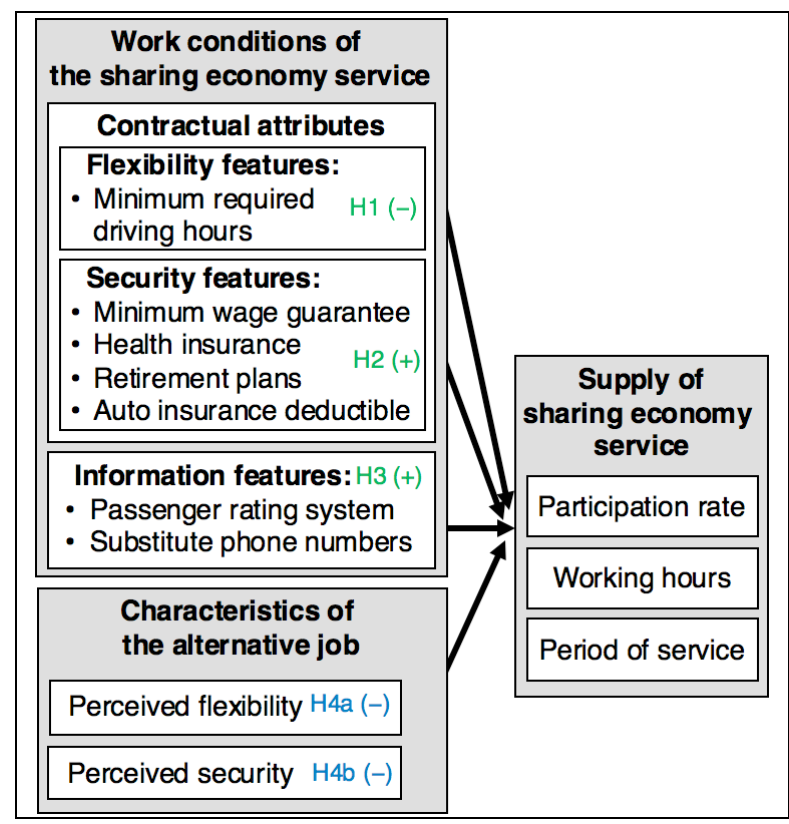

Figure 1. Framework and hypotheses

\begin{tabular}{|c|c|c|}
\hline Attribute & \begin{tabular}{|c} 
Option \\
1 \\
\end{tabular} & \begin{tabular}{|c|} 
Option \\
2 \\
\end{tabular} \\
\hline $\begin{array}{c}\text { Minimum required } \\
\text { driving hours per week }\end{array}$ & $\begin{array}{c}40 \\
\text { hours }\end{array}$ & $\begin{array}{c}20 \\
\text { hours }\end{array}$ \\
\hline $\begin{array}{l}\text { Health insurance } \\
\text { The ride-sharing company provides your } \\
\text { health insurance with average coverage. }\end{array}$ & Yes & Yes \\
\hline $\begin{array}{c}\text { Retirement } \\
\begin{array}{c}\text { The ride-sharing company matches all or } \\
\text { some of your retirement plan. }\end{array} \\
\end{array}$ & Yes & Yes \\
\hline $\begin{array}{c}\text { Minimum wage guarantee } \\
\text { The company covers the difference between } \\
\text { your hourly earning and minimum wage if your } \\
\text { acceptance rate is higher than } 80 \% \text {. }\end{array}$ & Yes & No \\
\hline $\begin{array}{c}\text { Passenger rating system } \\
\text { You can evaluate a passenger after providing } \\
\text { a ride. }\end{array}$ & No & No \\
\hline $\begin{array}{c}\text { Substitute phone numbers } \\
\text { Your phone number is disclosed when you } \\
\text { communicate with passengers }\end{array}$ & No & No \\
\hline $\begin{array}{c}\text { Auto insurance deductible } \\
\text { The company offers an insurance policy with a } \\
\$ 1,000 \text { or } \$ 2,500 \text { deductible and a } \$ 1 \text { million } \\
\text { of a total coverage for ride-sharing }\end{array}$ & & $p<50$ \\
\hline $\begin{array}{r}\square \text { I would drive with Option } \\
\square \text { I would drive with Option } \\
\square \text { I would not drive with eith } \\
\text { Figure 2. Example of a choic }\end{array}$ & & \\
\hline
\end{tabular}

\subsection{Flexibility features}

Our first hypothesis addresses the relationship between the level of flexibility and the intention to work. A requirement imposed by the platform owner to work for a minimum number of hours within a specified period reduces flexibility for suppliers. Suppliers may be willing to accept the arrangement if platform owners offer better benefits in exchange. However, without such an offset, the requirement will likely reduce the willingness to work for platform. Thus, we hypothesize:

H1. Requiring minimum work hours is negatively associated with suppliers' willingness to work.

\subsection{Employment security features}

The second set of hypotheses explores whether offering contractual attributes that improve employment security can increase a supplier's willingness to join the platform. Whether drivers earn the minimum wage while working for ridesharing platforms is controversial. It has stimulated persistent debates and collective actions by drivers. Prior research [50] reports that $74 \%$ of drivers make less than the minimum wage in certain U.S. states. Given these concerns, a guaranteed minimum wage may increase the willingness of drivers to work.

H2a. Guaranteeing a minimum wage is positively associated with suppliers' willingness to work.

We also examine the effect of offering a health insurance or retirement plan, sponsored by the ridesharing company. Such plans are not currently offered by most ridesharing platforms [37]. Previous research finds that health insurance and retirement plans increase job satisfaction $[1,3]$. Thus, offering health insurance and a retirement plan with matching contributions by the ridesharing company may increase drivers' willingness to work.

H2b. Offering a health insurance sponsored by the ridesharing company is positively associated with suppliers' willingness to work.

H2c. Offering a retirement plan with matching contribution by the ridesharing company is positively associated with suppliers' willingness to work.

Another security feature of ridesharing is the auto insurance deductible. For example, to reduce driver liability, Uber and Lyft currently provide an auto insurance policy with a $\$ 1$-million coverage amount and a $\$ 1,000$ or $\$ 2,500$ deductible, respectively, when drivers' ridesharing app is active. A lower deductible may increase suppliers' willingness to work.

H2d. Offering auto insurance with a lower deductible is positively associated with suppliers' willingness to work.

\subsection{Information features}

Information transparency features can increase participation in electronic markets [20]. The third set of 
hypotheses explores how information features of a P2P platform influence supplier participation. Some ridesharing platforms provide a passenger rating system and substitute phone numbers. A passenger rating system allows suppliers to evaluate an individual passenger, which contributes to a safer work environment in the long run. A substitute phone number function shows a dummy number to drivers and passengers when they communicate with each other. This feature helps both parties protect their personal information and privacy. Consequently, other things being equal, these information features are expected to increase willingness to work.

H3a. Providing a passenger rating system on the ridesharing service platform is positively associated with suppliers' willingness to work.

H3b. Providing a substitute phone number to protect personal information is positively associated with suppliers' willingness to work.

\subsection{Flexibility and security of alternative jobs}

Finally, we explore the relationships between characteristics of alternate jobs and the willingness to work for ridesharing platforms. Many ridesharing suppliers have other primary jobs, and the extent to which they are willing to engage with the platform may be affected by the flexibility and security of their other job.

We conjecture that when drivers have a primary job other than ridesharing, their interest in offering ridesharing services may be contingent on the flexibility of their primary job. For example, a more flexible work schedule may make it easier to find the time to offer ridesharing services. However, if the flexibility of drivers' primary job is high, due to their preference for flexibility, they may want to keep working in their primary job and work less for a ridesharing service.

Another interesting empirical question is whether the perceived security of the main job influences the willingness to take on a ridesharing job. Applying insights from security-potential and aspiration theory [26], we expect that security-enhancing service attributes will not increase the utility for a supplier if that individual perceives the security of the alternative main job to be sufficiently high. On the other hand, if the alternative main job does not fulfill a minimum level of security, the preference for a security-related attribute of the ridesharing service will be higher. Given the countervailing arguments, we propose a negative association to be tested:

H4a. The perceived flexibility level of an alternative job is negatively associated with suppliers' willingness to work for the ridesharing service.
H4b. The perceived security level of an alternative job is negatively associated with suppliers' willingness to work for the ridesharing service.

\section{Data and research design}

\subsection{Data}

We obtained online experimental data from ridesharing suppliers in the United States using Qualtrics online panels during April-May 2018. To compare differences between active and inactive drivers, ${ }^{2}$ samples of similar size for each group were recruited (204 active and 202 inactive drivers). Each sample is sufficiently larger than the required size using standard sampling size requirements [25, 34]. The unit cost per completed response was $\$ 15$.

Among 6,107 people who attempted to participate in the experiment, 133 participants were not able to proceed since they lived outside the United States. 3,933 people were screened out because they had not worked for ridesharing services. 681 inactive drivers were also screened out because the reasons they quit offering ridesharing services were not related to the work conditions. 489 people did not pass an attention check, and another 485 people did not complete the survey. The total number of data points obtained from the 406 participants is 7,308 (406 participants $\times 6$ choice sets $\times 3$ options).

The mean age in the final sample is 36 years old, and $54 \%$ are male. The proportion of individuals holding undergraduate or graduate degrees is $47 \%$, which is higher than that of the U.S. population in 2017, according to the U.S. Census Bureau. $87 \%$ of participants have driven for Uber and $52 \%$ for Lyft. On average, they have driven 33.4 hours per week for 1.4 years. The average wage for ridesharing was $\$ 20.08$ per hour. $37 \%$ of participants have an alternative primary job(s) other than ridesharing. Overall, active and inactive drivers have similar socio-demographic characteristics. Active drivers generally show shorter ridesharing experiences, shorter weekly driving hours, and lower hourly wage than inactive drivers. Thus, although the inactive drivers no longer drive, their level of engagement with ridesharing was slightly higher than that of current active drivers in the sample.

\subsection{Method and dependent variables}

To examine the effect of hypothetical work

\footnotetext{
${ }^{2}$ Following Hall and Krueger [21], inactive drivers are defined as drivers who have provided ridesharing services before but have not done so for the most recent six or more months.
} 
conditions on willingness to work, which is not observable, a discrete choice experiment was designed [46]. The key working conditions included in the choice experiment are five contractual attributes (minimum required driving hours per week, minimum wage guarantee, company-sponsored health insurance, company-sponsored retirement plan, and auto insurance with different deductible levels), and two information features (passenger rating system and substitute phone number function).

There are three levels of minimum required weekly driving hours $(0,20$, and 40 hours), two levels of the other six attributes, and two options composed of these seven attributes in each choice set. A full factorial experimental design would require $(3 \times 2 \times 2 \times 2 \times 2 \times 2 \times 2)^{2}$ $=36,864$ choice sets for combinations of the seven attributes, with multiple levels of each attribute and two choice options. To keep the number manageable, this study uses a fractional factorial design with six choice scenarios through D-optimal design and the OPTEX procedure.

To present participants with choice sets containing more varied options, we generated four different blocks which contain six choice sets. Each respondent was randomly assigned to one of the four blocks. Six choice sets were given in random order to avoid choices being affected by the order of the choice sets. The respondent first chooses Option 1, 2, or neither (see Figure 2). If Option 1 or 2 is selected, the respondent can decide to increase, decrease, or not change driving hours and future work period. A participant can choose not to work under conditions described in the two options if the incremental utility does not exceed that of the no-work option.

This choice experiment yields two types of responses: discrete and ordered categorical data. The dependent variables used to test $\mathrm{H} 1, \mathrm{H} 2$, and $\mathrm{H} 3$ are discrete (i.e., 1 when an option is chosen and 0 when the option is not chosen). The relative importance of each work condition compared to the other conditions in the choice set is examined by running a random parameter logistic (RPL) regression model as follows:

$$
U_{i a t}=\alpha_{i} h_{i a t}+\boldsymbol{\theta}^{\prime} \boldsymbol{v}_{i a t}+\varepsilon_{i a t}
$$

$U_{\text {iat }}$ is a binary utility variable equal to 1 for the chosen option and 0 for unchosen options. This equation presents individual $i$ 's utility derived from choosing an alternative $a$ among available alternatives in a choice set $C_{i t}$ and in choice situation $t$ [27]. $h_{\text {iat }}$ is the minimum required weekly driving hours, and $\boldsymbol{v}_{\text {iat }}$ is a vector composed of the other contractual and information features of a ridesharing service. $\alpha_{i}$ and $\boldsymbol{\theta}_{\boldsymbol{i}}$ are assumed to be normally distributed random parameters that are driver-specific.

The second type of responses, used to test $\mathrm{H} 4$, is ordered categorical data which shows drivers' willingness to change their participation rate, work hours, and work duration. For the chosen work option, the participant $i$ replies whether her willingness to work $\left(Y_{\text {iat }}\right)$ would decrease $\left(\operatorname{Pr}\left(Y_{\text {iat }}=1\right)\right)$, not change $\left(\operatorname{Pr}\left(Y_{i a t}=2\right)\right)$, or increase $\left(\operatorname{Pr}\left(Y_{i a t}=3\right)\right)$. We analyze the responses using the following generalized ordinal logistic regression model (e.g., [33]):

$\ln \left(Y_{\text {iat }}^{\prime}\right)=\ln \left(\frac{\pi_{\text {iat }}(x)}{1-\pi_{\text {iat }}(x)}\right)=\beta_{0 i a t}+\left(\beta_{1 i a t} X_{1}+\cdots+\beta_{\text {piat }} X_{p}\right)$

$X$ contains ridesharing attribute variables, ridesharing pattern variables (hourly rate, weekly work hours, percentage of income from ridesharing), employment characteristics (perceived flexibility and security of a primary job, whether the participant has a health insurance and/or retirement plan) and individual characteristics variables (age, gender, educational attainment, annual income, annual household income, household size, and race).

\section{Results}

We first test H1, H2, and H3 using the RPL model. Results in Table 1 show that all working condition attributes included in the choice set influence choices in the expected directions. Drivers' utility decreases when the ridesharing platform requires minimum driving hours (Hours). Their utility increases when the company provides health insurance (Health), matches with contributions all or some of drivers' retirement plan (Retirement), guarantees the city's minimum wage (Wage), or offers insurance with a smaller deductible (Deductible). A passenger rating system for safer work environments (Rating) and a substitute phone number for privacy protection (Phone) also increase drivers' utility. We also add an interaction term between Health and Deductible to check if the two insurance benefits may be perceived as a complement or substitute to each other, but the interaction term was not significant. The relatively large magnitude of coefficients on Health, Wage, and Retirement, compared to coefficients of other attributes, suggests these are important factors to increase drivers' willingness to work for ridesharing platforms.

Regarding Phone, active drivers' utility increases when the platform provides dummy phone number to passengers, helping drivers avoid unnecessary interactions after completing a ride. However, inactive drivers are not significantly affected by the availability of this function. This implies that while a private information protection function may not effectively motivate inactive drivers to work, the platform providing the private information protection function raises active drivers' willingness to work. 
Table 1. Parameter estimates from RPL

\begin{tabular}{|c|c|c|c|}
\hline Variables & All drivers & $\begin{array}{l}\text { Active } \\
\text { drivers }\end{array}$ & $\begin{array}{l}\text { Inactive } \\
\text { drivers }\end{array}$ \\
\hline Hours & $\begin{array}{l}-0.025^{* k \pi} \\
(0.006)\end{array}$ & $\begin{array}{l}-0.033^{\text {**x }} \\
(0.009)\end{array}$ & $\begin{array}{l}-0.0199^{* \pi} \\
(0.008)\end{array}$ \\
\hline Health & $\begin{array}{l}0.605^{* * *} \\
(0.085)\end{array}$ & $\begin{array}{l}0.5266^{\star x x} \\
(0.114)\end{array}$ & $\begin{array}{c}0.616 \\
(0.119)\end{array}$ \\
\hline Retirement & $\begin{array}{l}0.344^{* \star * *} \\
(0.064)\end{array}$ & $\begin{array}{l}0.269^{* \star *} \\
(0.085)\end{array}$ & $\begin{array}{l}0.392^{* * x} \\
(0.089)\end{array}$ \\
\hline Wage & $\begin{array}{c}0.461 \\
(0.051)\end{array}$ & $\begin{array}{c}0.459^{\star \star \star} \\
(0.073)\end{array}$ & $\begin{array}{c}0.506^{\star \star \star} \\
(0.074)\end{array}$ \\
\hline Deductible & $\begin{array}{c}0.145^{* *} \\
(0.068)\end{array}$ & $\begin{array}{r}0.141 \\
(0.092)\end{array}$ & $\begin{array}{r}0.132 \\
(0.105)\end{array}$ \\
\hline Rating & $\begin{array}{l}0.22^{* * *} \\
(0.046)\end{array}$ & $\begin{array}{l}0.225^{* \star *} \\
(0.064)\end{array}$ & $\begin{array}{c}0.184 \\
(0.067)\end{array}$ \\
\hline Phone & $\begin{array}{c}0.179 \\
(0.051)\end{array}$ & $\begin{array}{c}0.288^{* \star *} \\
(0.083)\end{array}$ & $\begin{array}{r}0.078 \\
(0.071)\end{array}$ \\
\hline $\begin{array}{l}\text { Health } \times \\
\text { Deductible } \\
\text { Opt Out }\end{array}$ & $\begin{array}{c}0.116 \\
(0.1)^{\star \star \star} \\
-2.322^{*} \\
(0.164)\end{array}$ & $\begin{array}{c}0.067 \\
(0.129) \\
-2.292^{\star * \star} \\
(0.221)\end{array}$ & $\begin{array}{c}0.215 \\
(0.151) \\
-2.33^{\star \star x} \\
(0.239)\end{array}$ \\
\hline$\overline{\mathrm{N}}$ & 406 & 204 & 202 \\
\hline $\begin{array}{l}\text { Adj.pseudo R- } \\
\text { squared }\end{array}$ & 0.18 & 0.18 & 0.20 \\
\hline
\end{tabular}

By estimating $\boldsymbol{w}_{\mathrm{i}}\left(=\boldsymbol{\theta}_{\boldsymbol{i}} /-\alpha_{i}\right)$ using Equation (1), drivers' preferences for the attributes can be presented in the unit of required driving hours for ridesharing, which the drivers must relinquish for preferable working conditions. Table 2 shows how many required hours drivers are willing to work for ridesharing to benefit from each attribute as a trade-off. On average, drivers are willing to work for ridesharing for 8.1 hours to benefit from a platform-sponsored health insurance, 6.5 hours to have access to a retirement plan, and 9.9 hours for a minimum wage guarantee. The interaction term shows drivers are willing to additionally work for 11.7 hours to have a health insurance and lower deductible at the same time. The willingness to work for health insurance, a retirement plan, and a minimum wage guarantee is higher for inactive drivers than for active drivers, suggesting that inactive drivers demand financial security more than active drivers, even though they need to sacrifice flexibility.

To explore the relationship between the flexibility and security of a driver's primary job and the willingness to work in a ridesharing job, we ran the generalized ordinal logistic regression on drivers who have other primary job(s) as employees, also known as paid employed. 152 drivers (37.4\% of all drivers), of which 98 were active and 54 inactive, have another primary job when working for ridesharing. The paid employed evaluate the perceived flexibility and
Table 2. Willingness to work

\begin{tabular}{|c|c|c|c|}
\hline Variable & All drivers & Active drivers & Inactive drivers \\
\hline \multirow{2}{*}{ Health } & 8.11 & $7.53^{\prime \prime}$ & 13.25 \\
\hline & {$[4.4,11.8]$} & {$[4.6,10.5]$} & {$[7.4,19.1]$} \\
\hline \multirow[t]{2}{*}{ Retirement } & $6.52^{\star \star \star \star \star^{\prime}}$ & $4.57^{* * \pi}$ & $9.39^{*+* t}$ \\
\hline & {$[4.8,8.2]$} & {$[2.4,6.8]$} & {$[6.1,12.7]$} \\
\hline \multirow[t]{2}{*}{ Wage } & $9.86^{* x^{2}}$ & $6.42^{x * t}$ & $12.07^{2 x+7}$ \\
\hline & {$[7.8,11.9]$} & {$[3.9,9.0]$} & {$[8.0,16.2]$} \\
\hline \multirow[t]{2}{*}{ Deductible } & -0.48 & -0.08 & -0.66 \\
\hline & {$[-3.3,2.4]$} & {$[-2.3,2.1]$} & {$[-5.3,4.0]$} \\
\hline \multirow[t]{2}{*}{ Rating } & $7.02^{2 x}$ & $3.37^{207}$ & $7.69^{\text {xax }}$ \\
\hline & {$[5.3,8.8]$} & {$[1.4,5.4]$} & {$[3.8,11.5]$} \\
\hline \multirow[t]{2}{*}{ Phone } & $3.11^{* \ldots+1}$ & $3.25^{x \times t}$ & 0.71 \\
\hline & {$[0.8,5.4]$} & {$[1.0,5.5]$} & {$[-3.4,4.9]$} \\
\hline Health $x$ & $11.67^{\mathrm{nkx}}$ & $4.95^{x \times t}$ & $10.15^{x \times x^{2}}$ \\
\hline Deductible & {$[7.3,16.1]$} & {$[1.6,8.3]$} & {$[2.9,17.4]$} \\
\hline $\mathrm{N}$ & 406 & 204 & 202 \\
\hline $\begin{array}{l}\text { Adj.pseudo } \\
\text { R-squared }\end{array}$ & 0.16 & 0.18 & 0.20 \\
\hline
\end{tabular}

Note: ${ }^{\star} p<.10,{ }^{\star \star} p<.05,{ }^{\star \star \star} p<.01 ;$ [95\% confidence interval]; Note that the purpose of comparing active and inactive drivers resides in recognizing differences in patterns of each group's preferences not in testing whether the difference in two groups' preferences is statistically significant.

security of their primary job using a scale of 1 to 4 following prior studies [33]. ${ }^{3}$

Table 3 shows active and inactive drivers' willingness to increase or decrease their work hours. Overall, the probability of increasing or decreasing active drivers' anticipated working hours for ridesharing ${ }^{4}$ is not significantly affected by perceived flexibility nor by security of their primary job. However, for inactive drivers the probability of increasing their willingness to work is negatively associated with flexibility and security of their primary job. ${ }^{5}$ This suggests that offering diversified work conditions in the sharing economy may complement a supplier's low flexibility or security from their current primary job.

\footnotetext{
${ }^{3}$ Perceived flexibility of the alternative job is evaluated using the question "How likely or unlikely do you think it is that you are able to choose when, where, and for how long you work for your current primary job?" based on the definition of job flexibility [23]. Following the previous literature [33] perceived security of the alternative job is evaluated using the question "How likely or unlikely do you think it is that you might lose your current primary job for some reasons over the next twelve months?" and participants reply to these questions by choosing one of the four levels of likelihood: "Not at all likely," "Not very likely," "Quite likely," or "Very likely" [33].

${ }^{4}$ For active drivers' anticipated participation rate and working period, the patterns of statistical significance on coefficients are consistent with the result of working hours.

${ }^{5}$ The coefficient of -10.4 is interpreted that the probability of increasing inactive drivers' willingness to work for ridesharing decreases by $10.4 \%$ as the level of perceived flexibility increases by one.
} 
Table 3. Generalized ordered logit estimation: Paid employed

\begin{tabular}{|c|c|c|c|c|c|c|}
\hline \multirow{4}{*}{ Variables } & \multicolumn{6}{|c|}{ Working hours for ride-sharing } \\
\hline & \multicolumn{4}{|c|}{ Active drivers } & \multicolumn{2}{|c|}{$\begin{array}{c}\text { Inactive } \\
\text { drivers }\end{array}$} \\
\hline & \multicolumn{2}{|c|}{$\operatorname{Pr}($ Decrease $)$} & \multicolumn{2}{|c|}{$\operatorname{Pr}($ Increase $)$} & \multicolumn{2}{|c|}{$\operatorname{Pr}($ Increase $)$} \\
\hline & $\begin{array}{c}\begin{array}{c}\text { Marginal } \\
\text { effects } \\
(\%)\end{array} \\
\end{array}$ & $z$ & $\begin{array}{c}\text { Marginal } \\
\text { effects } \\
(\%)\end{array}$ & $z$ & 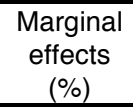 & $z$ \\
\hline \multicolumn{7}{|c|}{ Ridesharing attributes } \\
\hline Hours & $0.8^{x * x}$ & 5.4 & -0.1 & -0.6 & -0.1 & -0.5 \\
\hline Health & $-8.5^{* x *}$ & -4.3 & $8.2^{* x *}$ & 4.3 & $8.0^{x \times 1}$ & 3.2 \\
\hline Retirement & $-3.2^{*}$ & -1.9 & $3.1^{*}$ & 1.9 & $6.2^{\mathrm{x} *}$ & 3.0 \\
\hline Wage & $-6.8^{* x *}$ & -4.6 & $6.5^{\mathrm{xx}}$ & 4.6 & $7.4^{* * *}$ & 4.0 \\
\hline Deductible & $-2.8^{*}$ & -1.8 & 2.7 & 1.8 & 2.4 & 1.2 \\
\hline Rating & $-4.7^{* * *}$ & -2.8 & 1.1 & 0.7 & $6.8^{\mathrm{kx} x}$ & 3.8 \\
\hline Phone & $-4.9^{x \times x}$ & -3.3 & $4.7^{\mathrm{x \times x}}$ & 3.3 & 0.4 & -0.2 \\
\hline \multicolumn{7}{|c|}{ Employment characteristics } \\
\hline $\begin{array}{l}\text { Perceived } \\
\text { flexibility }\end{array}$ & -3.4 & -1.6 & 3.2 & 1.6 & $-10.4^{*}$ & -1.7 \\
\hline $\begin{array}{l}\text { Perceived } \\
\text { security }\end{array}$ & 4.0 & 0.9 & -2.1 & -0.9 & $-13.7^{* * *}$ & -4.4 \\
\hline $\mathrm{N}$ & 676 & & & & 324 & \\
\hline $\begin{array}{l}\text { Pseudo R- } \\
\text { squared }\end{array}$ & 0.16 & & & & 0.49 & \\
\hline
\end{tabular}

Note: ${ }^{\star} p<.10,{ }^{\star \star} p<.05,{ }^{\star \star \star} p<.01$; Controls: demographic characteristics, ridesharing work patterns, other employment characteristics; $N(676,324)$ is the number of responses from 98 active drivers and 54 inactive drivers, respectively. This categorical data is not balanced as participants are asked to report the willingness to change their work intention only if they choose a work option.

\section{Conclusion}

\subsection{Findings and contributions}

In the discrete choice experiment, drivers reveal their preferences by choosing options in choice sets composed of flexibility, security, and information features. We find that drivers' willingness to work for ridesharing generally increases when the ridesharing company provides a minimum wage guarantee, company-sponsored benefit plans, and information features that protect drivers, although they may need to relinquish flexibility by providing a ridesharing service for minimum required working hours. The choice experiment results suggest that providing higher security in working conditions appeals particularly to inactive drivers. More generally, platform companies can focus on offering job security to lure inactive suppliers back to the platform.

Regarding information attributes, we find that active drivers value features that prevent unwanted personal information disclosure more than inactive drivers do. We also find a negative association between inactive drivers' willingness to work for ridesharing and perceived flexibility and security of their primary job. This relationship shows the sharing economy can play a role in complementing low flexibility or security in working conditions of a supplier's main job.

Our findings make three contributions to the research literature. First, this study extends existing research by providing empirical evidence for platform managers to identify which work conditions are important to increase suppliers' utility, which can increase the supply of services in their platform. Prior studies have mainly focused on the platform's ownerdeveloper relationship or the platform's ownerconsumer relationship. This study underscores the importance of contracts between platform owners and suppliers, viewing suppliers as active main players and decision makers, rather than as passive players who accept any work conditions. Second, this study adds to the literature on information transparency. While previous studies have primarily focused on $\mathrm{B} 2 \mathrm{~B}$ or B2C markets, we investigate the effect of information features which contribute to establishing trust in $\mathrm{P} 2 \mathrm{P}$ transactions on suppliers' willingness to partner with a platform. Third, this study contributes to the literature on a recent perspective in labor economics asserting a positive relationship between flexibility and security (referred to as "flexicurity"). This approach has gained traction in many countries as a possible response to the new work conditions in the digital economy. Finally, as far as we know, this is the first study to provide empirical evidence on the potential complementarities between the security of sharing economy suppliers' main job and a sharing economy job with companysponsored benefit plans.

This study also offers practical implications that go beyond ridesharing services. It helps design supplier attraction and retainment strategies for companies that might face conflicts related to suppliers' working conditions and concerns about the fairness of the distribution of benefits from sharing economy services. Granting the option to choose benefits and better working conditions to suppliers can improve service quantity and quality, enhance corporate image, improve customer service, and ultimately lead to higher profits.

Regulators and authorities should consider that a large share of individuals $(63 \%$ of participants in our study) work for ridesharing as a primary means of living. Considering that offering a minimum wage is still one of the most important and controversial issues for ridesharing platforms [50], policy makers could introduce measures that require platforms to notify suppliers whether they will earn the minimum wage or not, and provide incentives for platform companies to 
improve their benefit plans. Moreover, considering inactive drivers' low concerns or lack of awareness about the risk of personal information disclosure, regulators should take more care of and monitor potential related issues to prevent misuse of personal information.

\subsection{Directions for future research}

This study only touches the surface of trade-offs in working conditions for suppliers in the sharing economy. We can think of two possible interesting directions for future research. First, a longitudinal study to observe actual supply decisions can complement this study, since we could not capture them in our cross-sectional design. Moreover, the cross-sectional nature of the data makes it difficult to establish reasonable conclusions on causality. Thus, studies that capture dynamics between drivers' decision to work and working conditions will provide valuable insights.

Another avenue for future research is to study additional working conditions that this study did not capture. To minimize confusion across participants, our experiment setting only contains core descriptions of the choice experiment, avoiding much detailed explanation of each work condition. For example, drivers' expectation of a standard health insurance coverage may differ. Future studies may investigate drivers' work decision under more differentiated benefit plan conditions.

In sum, this study increases our understanding of the factors that motivate suppliers to join a platform and increase their willingness to work. More generally, there are tangible implications for platform design and governance related to the trade-offs between offering flexibility and security to suppliers in the sharing economy.

\section{References}

[1] Artz, B. "Fringe benefits and job satisfaction". International Journal of Manpower, 31(6), 2010, pp. 626644.

[2] Awad, N.F. and Krishnan, M.S. "The personalization privacy paradox: an empirical evaluation of information transparency and the willingness to be profiled online for personalization”. MIS Quarterly, 30(1), 2006, pp. 13-28.

[3] Barringer, M.W. and Milkovich, G.T. "A theoretical exploration of the adoption and design of flexible benefit plans: A case of human resource innovation. Academy of Management Review, 23(2), 1998, pp. 305-324.

[4] Benbya, H., and Van Alstyne, M.W. "How to find answers within your company". MIT Sloan Management Review, 52(2), 2011, pp. 65-76.
[5] Borleis, M.W. The Handbook of Employee Benefits, Irwin, Chicago, 1996.

[6] Bredgaard, T. and Madsen, P.K. "Farewell flexicurity? Danish flexicurity and the crisis". Transfer: European Review of Labour and Research, 24(4), 2018, pp. 375-386.

[7] Busquets, J. "Orchestrating Smart Business Network dynamics for innovation”. European Journal of Information Systems, 19(4), 2010, pp.481-493.

[8] Clemons, E.K., Dewan, R.M., Kauffman, R.J., and Weber, T.A. "Understanding the information-based transformation of strategy and society". Journal of Management Information Systems, 34(2) 2017, pp. 425-456.

[9] Crank, A.L. “O'Connor v. Uber Technologies, Inc.: The dispute lingers-are workers in the on-demand economy employees or independent contractors". American Journal of Trial Advocacy, 39, 2015, pp. 609.

[10] De Reuver, M. "Governing mobile service innovation in co-evolving value networks". Dissertation. Technische Universiteit Delft. 2009.

[11] De Reuver, M., Bouwman, H., Prieto, G., and Visser, A. "Governance of flexible mobile service platforms". Futures, 43(9), 2011, pp. 979-985.

[12] Dewan, R.M., Freimer, M.L., and Jiang, Y. "A temporary monopolist: Taking advantage of information transparency on the Web". Journal of Management Information Systems, 24(2), 2007, pp. 167-194.

[13] DiMaggio, P. and Hargittai, E. "From the 'digital divide' to 'digital inequality': Studying Internet use as penetration increases". Princeton: Center for Arts and Cultural Policy Studies, Woodrow Wilson School, Princeton University, 4(1), 2001.

[14] Ehrenberg, R. and Smith, R. Modern Labor Economics: Theory and Public Policy, Routledge, 2017.

[15] Edelman, B.G. and Geradin, D. "Efficiencies and regulatory shortcuts: How should we regulate companies like Airbnb and Uber". Stanford Tech Law Review, 19, 293, 2016.

[16] Eyal, N. Hooker: How to build habit-forming products, Toronto: Penguin Canada, 2014.

[17] Farrell, D. and Greig, F. "Paychecks, paydays, and the online platform economy: Big data on income volatility". JP Morgan Chase Institute, 2016.

[18] Ghazawneh, A. and Henfridsson, O. "Governing thirdparty development through platform boundary resources". In the International Conference on Information Systems (ICIS), 2010.

[19] Granados, N., Gupta, A., and Kauffman. R.J. "Transparency strategy in internet-based selling." In K. Tomak (Ed.), Advances in the Economics of Information Systems, 2005, pp. 80-112. Harrisburg, PA: Idea Group.

[20] Granados, N., Gupta, A., and Kauffman. R.J. "Research commentary-information transparency in business-toconsumer markets: concepts, framework, and research agenda". Information Systems Research, 21(2), 2010, pp. 207-226. 
[21] Hall, J.V. and Krueger, A.B. "An Analysis of the Labor Market for Uber's Driver-Partners in the United States". ILR Review, 71(3), 2015, pp. 705-732.

[22] Hargittai, E. "Second-level digital divide: Differences in people's online skills". Frist Monday, 7(4), 2002.

[23] Hill, E.J., Grzywacz, J.G., Allen, S., Blanchard, V.L., Matz-Costa, C., Shulkin, S., and Pitt-Catsouphes, M. "Defining and conceptualizing workplace flexibility. Community, Work and Family". 11(2), 2008, pp.149-163.

[24] Jain, A. "Apps Marketplaces and the telecom value chain”. IEEE Wireless Communications, 18(4), 2011, pp.4-5.

[25] Johnson, R. and Orme, B. "Getting the most from CBC. Sequim: Sawtooth Software Research Paper Series", Sawtooth Software, 2003.

[26] Lopes, L.L., and Oden, G.C. "The role of aspiration level in risky choice: A comparison of cumulative prospect theory and SP/A theory". Journal of mathematical psychology, 43(2), 1999, pp. 286-313.

[27] Loureiro, M.L. and Umberger, W.J. "A choice experiment model for beef: What US consumer responses tell us about relative preferences for food safety, country-oforigin labeling and traceability". Food Policy, 32(4), 2007, pp. 496-514.

[28] Madsen, K, "The Danish model of "flexicurity" - a paradise with some snakes”. In: Sarfati, H., Bonoli, G. (Eds.), Labour Market and Social Protection Reforms in International Perspective. Parallel or Converging Tracks?. Ashgate/ISSA: Aldershot, 2002, pp. 243-265.

[29] Manner, J., Nienaber, D., Schermann, M., and Krcmar, H. Governance for Mobile Service Platforms: a literature Review and Research Agenda. In ICMB, 2012, pp. 14.

[30] Markus, M.L. "The governance of free/open source software projects: monolithic, multidimensional, or configurational?" Journal of Management and Governance, 11(2), 2007, pp. 151-163.

[31] McNamara, B. "Airbnb: A not-so-safe resting place". Journal on Telecommunication and High Technology Law, 13, 2015, pp. 149-170.

[32] Muffels, R. and Luijkx, R. "Job mobility and employment patterns across European welfare states. Is there a "trade-off" or a "double bind" between flexibility and security?". Institute for Labour Studies, Amsterdam. Retrieved, 25(5), 2010.

[33] Origo, F. and Pagani, L. "Flexicurity and job satisfaction in Europe: The importance of perceived and actual job stability for well-being at work". Labour Economics, 16(5), 2009, pp. 547-555.

[34] Orme B. "Sample size issues for conjoint analysis studies”. Sequim: Sawtooth Software Technical Paper. 1998.

[35] Parker, G.G., Van Alstyne, M.W., and Choudary, S.P. "Platform Revolution: How Networked Markets Are Transforming the Economy--And How To Make Them Work For You”. WW Norton and Company, 2016.

[36] Puschmann, T. and Alt, R. "Sharing economy". Business and Infomation Systems Engineering, 58(1), 2016, pp. 93-99.

[37] Rolf, D. (2016). The Fight for Fifteen: The Right Wage for a Working America. New Press, 2016.

[38] Rudmark, D. and Ghazawneh, A. "Third-party development for multi-contextual services: on the mechanisms of control". In ECIS Proceedings, 162, 2011.

[39] Schlagwein, D., Schoder, D., and Fischbach, K. "Openness in the orchestration of ecosystems: a resourcebased perspective". Sprouts: Working Papers on Information Systems, 10(78), 2010.

[40] Schnackenberg, A.K., and Tomlinson, E.C. "Organizational transparency: A new perspective on managing trust in organization-stakeholder relationships". Journal of Management, 42(7), 2016, pp. 1784-1810.

[41] Scholz, T. "Platform cooperativism: Challenging the corporate sharing economy", Rosa Luxemburg Foundation, 2016.

[42] Schor, J.B. and Attwood-Charles, W. "The "sharing" economy: labor, inequality, and social connection on for-profit platforms". Sociology Compass, 11(8), 2017, e12493.

[43] Sundararajan, A. The Sharing Economy: The End of Employment and The Rise of Crowd-Based Capitalism. MIT Press. 2016.

[44] Tiwana, A. "Governance-knowledge fit in systems development projects". Information Systems Research, 20(2), 2009, pp. 180-197.

[45] Tiwana, A., Konsynski, B., and Bush, A.A. "Research commentary-Platform evolution: Coevolution of platform architecture, governance, and environmental dynamics". Information Systems Research, 21(4), 2010, pp. 675-687.

[46] Train, K. Discrete Choice Methods with Simulation. Cambridge University Press, 2009.

[47] Weber, T.A. "Intermediation in a sharing economy: insurance, moral hazard, and rent extraction". Journal of Management Information Systems, 31(3), 2014, pp. 35-71.

[48] Weber, T.A. "Smart products for sharing". Journal of Management Information Systems, 34(2), 2017, pp. 341-368.

[49] Zhu, K. "Information transparency of business-tobusiness electronic markets: A game-theoretic analysis". Management Science, 50(5), 2004, pp. 670-685.

[50] Zoepf, S.M., Chen, S., Adu, P., and Pozo, G. "The economics of ride-hailing: driver revenue, expenses, and taxes," CEEPR WP, 5, 2018. 